\title{
Prevalence, risk factors and seasonal variations of different Enteropathogens in Lebanese hospitalized children with acute gastroenteritis
}

Ali Salami ${ }^{1 * \dagger} \mathbb{D}$, Hadi Fakih ${ }^{2+}$, Mohamed Chakkour ${ }^{3+}$, Lamis Salloum ${ }^{1 \dagger}$, Hisham F. Bahmad ${ }^{4,5}$ and Ghassan Ghssein ${ }^{1 *}$

\begin{abstract}
Background: Acute gastroenteritis (AGE) is a major cause of pediatric morbidity and mortality around the world. It remains a frequent reason for infection-related admissions to emergency units among all age groups. Following the Syrian refugee crisis and insufficient clean water in our region, we sought to assess the etiological and epidemiological factors pertaining to AGE in South Lebanon.

Methods: In this multi-center cross sectional clinical study, we analyzed the demographic, clinical and laboratory data of 619 Lebanese children from the age of 1 month to 5 years old who were admitted with AGE to pediatrics departments of three tertiary care centers in South Lebanon.

Results: Our results revealed that males had a higher incidence of AGE (57.3\%) than females. Enteropathogens were identified in 332/619 (53.6\%) patients. Single pathogens were found in 294/619 (47.5\%) patients, distributed as follows: Entamoeba histolytica in 172/619 (27.8\%) patients, rotavirus in 84/619 (13.6\%), and adenovirus in 38/619 (6.1\%). Mixed co-pathogens were identified in 38/619 (6.1\%) patients. Analyzing the clinical manifestations indicated that $E$. histolytica caused the most severe AGE. In addition, children who received rotavirus vaccine were significantly less prone to rotavirus infection.

Conclusions: Our findings alluded to the high prevalence of $E$. histolytica and other unidentified enteropathogens as major potential causes of pediatric AGE in hospitalized Lebanese children. This should drive us to widen our diagnostic panel by adopting new diagnostic techniques other than the routinely used ones (particularly specific for the pathogenic amoeba E. histolytica and for the unidentified enteropathogens), and to improve health services in this unfortunate area of the world where insanitary water supplies and lack of personal hygiene represent a major problem.
\end{abstract}

Keywords: Acute gastroenteritis, E. histolytica, Unidentified enteropathogens, Pediatric, Lebanon

\section{Background}

Acute Gastroenteritis (AGE) is a common pediatric illness. In the Middle East region and Lebanon specifically, AGE persists as the second major cause of pediatric mortality and morbidity following acute lower respiratory tract

\footnotetext{
* Correspondence: a.salami@ul.edu.lb; ghassan.ghssein@gmail.com

${ }^{+}$Ali Salami and Hadi Fakih contributed equally to this work as co-first authors. Mohamed Chakkour and Lamis Salloum contributed equally to this work as co-second authors.

${ }^{1}$ Rammal Hassan Rammal Research Laboratory, Physio-toxicity (PhyTox) Research Group, Lebanese University, Faculty of Sciences ( $)$, Nabatieh, Lebanon

Full list of author information is available at the end of the article
}

infections [1, 2] and remains a frequent form of presentation due to infectious causes to the emergency units among all age groups [3-5]. Consequently, diarrheal disease is one of the major causes of death globally, where it mostly affects youngsters in undeveloped countries and represents a significant cause of morbidity among children under the age of five in developing countries $[6,7]$.

In addition to diarrhea, other major symptoms of AGE have been reported to consequently lead to increase in morbidity in severe cases, including vomiting, nausea, weight loss, abdominal pain and dehydration [3, 7]. Gastroenteritis annually affects 3 to 5 billion children worldwide

(c) The Author(s). 2019 Open Access This article is distributed under the terms of the Creative Commons Attribution 4.0 International License (http://creativecommons.org/licenses/by/4.0/), which permits unrestricted use, distribution, and 
and is responsible for $12 \%$ of deaths in children less than 5 years old every year [8]. In developed countries, 1 in 25 children below 5 years of age is diagnosed with AGE [4]; for instance, more than 5 million cases of pediatric AGE are diagnosed in Canada every year [9].

There are several etiologies for AGE, including bacterial, viral, and parasitic enteropathogens. Globally, rotavirus is considered the major cause of infantile AGE [3]. It is considered one of the most significant causes of diarrhea during the first years of life [10]. It was estimated that 440,000 children deaths occur worldwide every year due to rotavirus infections before the release of the rotavirus vaccine [11]. In 2011, data from the coordinated global network for rotavirus surveillance of the World Health Organization (WHO) showed that $37-53 \%$ of children hospitalized with diarrhea were infected with rotavirus in regions where vaccination has not been broadly applied [12]. In Lebanon, particularly, previous studies showed a prevalence of 27.7 and $30.6 \%$ of rotavirus [13, 14]. Nowadays, rotavirus vaccination is widely available for children in almost all countries and it is highly recommended by physicians [15].

Other than rotavirus, Entamoeba histolytica - an intestinal protozoan parasite - is associated with diarrheal diseases, especially human amoebiasis, with a global health concern mainly in developing countries. It is a leading cause of death from parasites around the world and is responsible for more than 50 million infected cases every year, among which 40,000-110,000 patients eventually die [16, 17]. In fact, E. histolytica was listed as the second highest priority parasite by the National Institute of Health and Infectious Diseases in the United States [18]. A previous study in Beirut, Lebanon, showed that $22.3 \%$ of the cases hospitalized with AGE were infected with E. histolytica [14].

Nevertheless, regardless of being a global morbidity and mortality issue among children, AGE preventive measures are achievable via implementing personal and food hygiene, usage of sanitized water, applying vaccination against potential AGE causing viruses and bacteria, and advocating breastfeeding and appropriate nutrition. Such measures and others can heavily prevent the spread of the disease [19].

A recent study performed by our team in South Lebanon evaluated common causes of AGE among hospitalized children during the period of summer 2014. Results from this study indicated that $40.4 \%$ of all hospitalized cases in children were due to AGE, with rotavirus and $E$. histolytica being the major identified disease-causing pathogens [20]. To widen our knowledge regarding the incidence, age distribution, etiologies, AGE incidence throughout the different months of the year for each pathogen involved, protective factors, and correlation between AGE causes and severity of the disease among hospitalized children in Southern Lebanon, we performed this current study with a larger sample size, to cover most of the South district. In this multi-center study, 3058 Lebanese children admitted to the pediatrics departments were enrolled, among which 619 were diagnosed with AGE. Frequency and etiology of infectious gastroenteritis was then determined using the available routine laboratory tests.

\section{Methods}

\section{Patients' selection}

During a one-year period, from the 1st of January 2017 until the 31st of December 2017, we collected and analyzed clinical, demographic and laboratory data of 619 Lebanese hospitalized children, aged between 1 month and 5 years old (60 months old), with acute gastroenteritis (AGE) who were admitted to pediatrics departments of three tertiary care centers ( 2 governmental and 1 private) in South Lebanon.

Patients included in this study were hospitalized children with AGE or diarrhea, defined as the occurrence of three or more of loose or liquid stools per day (or more frequent passage than is normal for the individual) [19]. We excluded from this study: children with chronic diarrhea, immunodeficiency, malnutrition and those with multiple malformations, since these parameters can negatively affect the length of hospitalization and the severity of the disease which may constitute a disruption in the analysis of our results.

\section{Clinical variables}

Data were collected as follow:

i) Demographic data including: age, gender, date of diagnosis, breast feeding, type of drinking water, housewife mother, family size and the vaccination history to determine if any dose of the two rotavirus vaccines (Rotarix from GlaxoSmithKline Biologicals, Rixensart, Belgium; or Rotateq from Merck Sharp \& Dohme Corp, Whitestation, NJ, USA) that are available and approved in Lebanon, was given.

ii) Clinical data including: AGE signs such as fever, diarrhea, vomiting, dehydration, and blood and mucus in stool, in addition to the duration of hospitalization and the calculation of the index of severity "Vesikari Score" [21].

iii) Laboratory findings including: blood levels of WBCs, RBCs, hemoglobin (HGB), hematocrit (HCT), blood sugar (BS), and C-reactive protein (CRP), in addition to the results of stool analysis such as microscopy for ova and parasites, searching for E. histolytica by the trichrome stain technique. Although WHO states that E. histolytica stool antigen detection test is more specific for the pathogenic amoeba E. histolytica than the classic stool 
ova and parasite examination, the latter was the one still utilized in almost all healthcare centers in South Lebanon, including the three tertiary healthcare centers in our study, which reflects the importance of improving health services in this unfortunate area of the world (South Lebanon). Laboratory findings also included the quick identification tests "rapid tests" for adenovirus (CerTest; Biotec, Zaragoza, Spain) and rotavirus (CerTest), and if available the results of bacterial coproculture.

\section{Laboratory methods and studies}

Fresh stool samples were acquired and analyzed, once received by the laboratory and within less than one hour, for the presence of infectious agents as previously described in a study from our group [20]. In brief, rotavirus and adenovirus kit tests (CerTest; Biotec, Zaragoza, Spain) were used for viral detection [22], and stool cultures were performed, when requested by the treating physician, by the direct and indirect culture methods [20].

\section{The sample size and power of the study}

The level of confidence in this study was set at 95\% with alpha error $=0.05$. With a previously detected prevalence of AGE in inpatient cases at our locality of 40.4\% [20], the power of this study was settled at $90 \%$ with beta error of 0.10 . The estimated sample size was 370 . The research team decided to increase the sample size by adding 249 (Total number 619) patients to increase the power of the study.

\section{Statistical analysis}

Statistical Package for Social Science software (SPSS, Inc.), version 20.0, was used for conducting the statistical analyses. This software was used as well for data management and cleaning. Descriptive statistics were carried out and reported as frequencies and percentages for categorical variables, and as means and standard deviation $( \pm)$ for continuous ones. After tabulating the patients' clinical characteristics, baseline comparisons between the five studied groups were performed using Kruskall Wallis test for continuous variables. Chi-square test was used to evaluate any significant difference between the categorical variables. Associations between the infectious agents (unidentified pathogens, rotavirus, E. histolytica, adenovirus, and mixed enteropathogens) as dependent variables on one hand, and breast-feeding, rotavirus vaccine, intake of sanitary water, and age as independent variables on the other hand, were determined using five separate logistic regression models, a model for each infectious agent. The level of significance was set at $P<0.05$ for all statistical analyses.

\section{Results}

\section{Socio-demographic characteristics}

During the period between January 2017 and December 2017, out of 3058 Lebanese patients admitted to pediatrics departments of three tertiary healthcare centers in SouthLebanon, 619 patients suffering from acute gastroenteritis (AGE) were diagnosed due to different enteropathogens. Among those, $42.7 \%$ were females and $57.3 \%$ were males. Patients were divided into six age groups between 1 and 60 months $(1-3,4-11,12-23,24-35,36-47,48-60)$, as previously described [13]. The mean family size of patients was $4.1,76.4 \%$ of them had intake of sanitary water, $25.9 \%$ of mothers were defined as housewives, $68.5 \%$ of patients were breastfed, and $53.5 \%$ had taken the rotavirus vaccine.

Regarding the monthly distribution of AGE cases, the highest number was clearly observed during the warm period especially between July and August (92 and 91 cases, respectively) of hospitalized children (Fig. 1).

\section{Enteropathogenic causes}

Different groups of enteropathogens were detected among patients. E. histolytica was the lead known enteropathogen with $27.8 \%$ of cases, followed by rotavirus, adenovirus and Mixed group (two or more identified enteropathogens) with 13.6, 6.1 and $6.1 \%$, respectively. $46.4 \%$ of cases were classified as unidentified enteropathogens and this might be due to the absence of advanced bacterial diagnosis and lack of detection of some viruses (astrovirus and norovirus) and protozoan parasites (Giardia lamblia). In fact, bacterial diagnosis was done just when it was requested by the treating physician (in $11.3 \%$ of cases).

\section{Demographic characteristics among the five studied groups}

The distribution of age revealed that $55.9 \%(346 / 618)$ of our patients were aged between 4 and 23 months. The distribution of age groups among the different groups of enteropathogens was highly remarkable in children aged between 4 and 23 months $(P=0.031)$. Concerning the sex distribution of our patients, even in the presence of a slight difference between the percentages of the two sexes in case of unidentified group, no significant difference was observed between the five groups. Among the different demographic characteristics, patients who were breastfed, rotavirus immunized $(P<0.001)$ and patients who take sanitary water had the highest percentages of infection by unidentified agents or E. histolytica (Table 1).

Regarding the monthly distribution of each enteropathogen in this study, our results showed that rotavirus is more prevalent in January compared to its yearly average, whereas the unidentified group had an important peak in July and August, compared to its yearly average. A significant peak was also observed in August for 


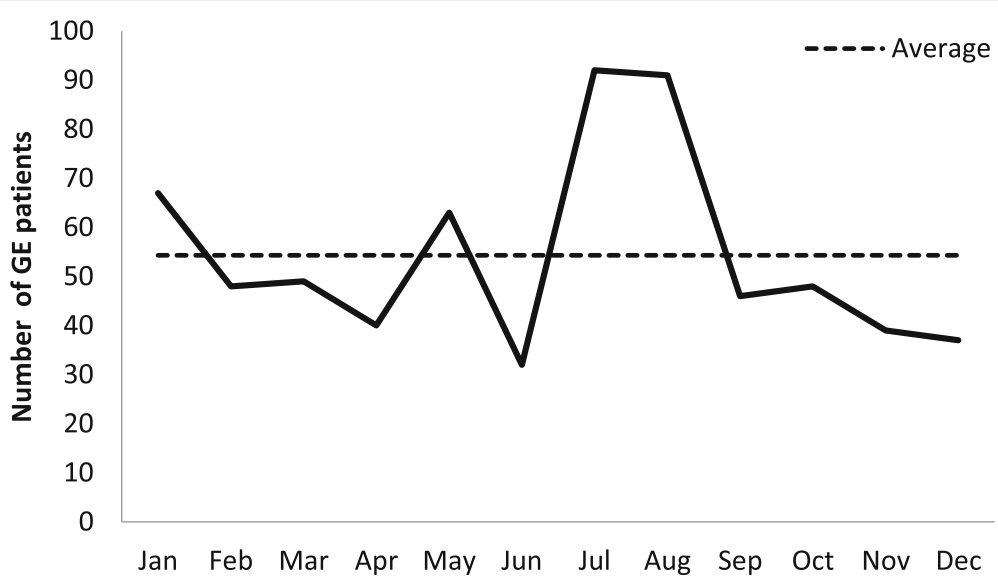

Fig. 1 Number of acute gastroenteritis patients according to the month of admission

adenovirus group. Concerning E. histolytica, it had small fluctuations around its yearly average (Fig. 2).

\section{Clinical characteristics among the five studied groups}

Table 2 shows the clinical and laboratory data of patients among the five studied groups. The most common sign between the five groups was diarrhea $78.0 \%$, followed by fever $74 \%$ and vomiting $44.7 \%$. Fever was significantly higher $(P=0.001)$ in both unidentified and E. histolytica groups compared to the three other groups (74.9 and $83.1 \%$, respectively), whereas vomiting was significantly higher in viral and mixed groups $(P<0.001)$. There was a significant difference between the means of Vesikari score $(P=0.005)$ in the five studied groups. Regarding diarrhea and duration of hospitalization, significant differences were observed among the five groups $(P=0.016$ and $P=0.003$, respectively) (Table 2 ).

Laboratory findings presented significantly higher average of WBC, RBC, HGB, BS and CRP (>30 mg/dL highly positive) in $E$. histolytica than the 4 other groups $(P<0.001, P<0.001, P=0.008, P<0.001$ and $P<0.001$, respectively) (Table 2 ).

\section{Effect of breast feeding, rotavirus vaccination, and sanitary water on different pathogens}

We analyzed the protective factors from enteropathogens associated with AGE. Results showed that in general, breastfed children might be less prone to unidentified enteropathogens, adenovirus and mixed infections. On the other hand, the rotavirus vaccine significantly protects against rotavirus $(P<0.001)$. However, the children given rotavirus vaccine had AGE attributed to E. histolytica, adenovirus and other enteropathogens not targeted in the study setting. Drinking sanitary water was associated with a lower frequency of unidentified enteropathogens, E. histolytica and adenovirus (Table 3).

\section{Pathogens predisposition according to age}

It was found that rotavirus increased significantly in children from 12 to 23 months and children from 36 to 47 months $(P=0.047$ and $P=0.014$ respectively) while adenovirus increased significantly only in children from 36 to 47 months $(P=0.035)$ compared to the reference age group (48-60). However, children between 24 to 35 and children between 36 to 47 months were less prone to have E. histolytica in comparison to the reference age group (48-60) $(P=0.035$ and $P=0.023$ respectively). Results are shown in Table 4.

\section{Discussion}

Most major health concerns among children under 5 years of age in Lebanon and other developing countries are respiratory and diarrheal diseases such as acute gastroenteritis (AGE) [1]. The etiologies of AGE comprise a long list of viral, parasitic and bacterial pathogens that have been identified in infected individuals. Identifying the enteropathogens that account for AGE is crucial for the application of suitable public and clinical procedures to control the disease [23]. This study was performed for a period of 1 year between January and December 2017 and covered a large area of Southern Lebanon. To the best of our knowledge, this is one of few studies conducted in Lebanon to determine the pathogens causing AGE among Lebanese children below the age of five and to check whether there exists a relation between the different etiologies of the illness and its severity and seasonal variations, using routine common laboratory methods. In our study, we included 619 Lebanese pediatric patients hospitalized with AGE out of 3058 patients admitted to the pediatrics departments during that period.

Among all the AGE hospitalized pediatric patients, we were able to identify the enteropathogen causing the illness in $53.6 \%$ of the cases only, which is less than the 
Table 1 Demographic characteristics of patients among the five studied groups

\begin{tabular}{|c|c|c|c|c|c|c|c|}
\hline $\begin{array}{l}\text { Demographic } \\
\text { Characteristics }\end{array}$ & $\begin{array}{l}\text { Unidentified } \\
\text { group I n/N (\%) }\end{array}$ & $\begin{array}{l}\text { rotavirus group } \\
\text { II n/N (\%) }\end{array}$ & $\begin{array}{l}\text { E. histolytica } \\
\text { group III n/N (\%) }\end{array}$ & $\begin{array}{l}\text { adenovirus group } \\
\text { IV n/N (\%) }\end{array}$ & $\begin{array}{l}\text { Mixed group } \\
\text { V n/N (\%) }\end{array}$ & Total GE N & $P$-value \\
\hline Age (months) & & & & & & & 0.031 \\
\hline $1-3$ & 28/52 (53.8\%) & $5 / 52$ (9.6\%) & 16/52 (30.8\%) & 2/52 (3.8\%) & 1/52 (1.9\%) & 52 & \\
\hline $4-11$ & 74/178 (41.6\%) & 26/178 (14.6\%) & 50/178 (28.1\%) & 12/178 (6.7\%) & 16/178 (9.0\%) & 178 & \\
\hline $12-23$ & 76/168 (45.2\%) & 26/168 (15.5\%) & 46/168 (27.4\%) & 7/168 (4.2\%) & 13/168 (7.7\%) & 168 & \\
\hline 24-35 & 50/94 (53.2\%) & 11/94 (11.7\%) & 22/94 (23.4\%) & 9/94 (9.6\%) & 2/94 (2.1\%) & 94 & \\
\hline $36-47$ & 26/57 (45.6\%) & 12/57 (21.1\%) & 11/57 (19.3\%) & 7/57 (12.3\%) & $1 / 57(1.8 \%)$ & 57 & \\
\hline $48-60$ & $33 / 69(47.8 \%)$ & 4/69 (5.8\%) & 27/69 (39.1\%) & 1/69 (1.4\%) & 4/69 (5.8\%) & 69 & \\
\hline Total & 287 & 84 & 172 & 38 & 37 & 618 & \\
\hline Gender & & & & & & & 0.250 \\
\hline Female & 111/266 (38.7\%) & $36 / 266$ (42.9\%) & $85 / 266$ (49.4\%) & 16/266 (42.1\%) & 18/266 (47.4\%) & 266 & \\
\hline Male & 176/353 (61.3\%) & 48/353 (57.1\%) & $87 / 353(50.6 \%)$ & 22/353 (57.9\%) & 20/353 (52.6\%) & 353 & \\
\hline Total & 287 & 84 & 172 & 38 & 38 & 619 & \\
\hline Breast feeding & & & & & & & 0.094 \\
\hline No & $84 / 175$ (48.0\%) & 25/175 (14.3\%) & $36 / 175$ (20.6\%) & 15/175 (8.6\%) & 15/175 (8.6\%) & 175 & \\
\hline Yes & 169/381 (44.4\%) & $55 / 381(14.4 \%)$ & 115/381 (30.2\%) & 20/381 (5.2\%) & 22/381 (5.8\%) & 381 & \\
\hline Total & 253 & 80 & 151 & 35 & 37 & 556 & \\
\hline Rotavirus vaccine & & & & & & & 0.000 \\
\hline No & 108/256 (42.2\%) & $53 / 256(20.7 \%)$ & $66 / 256(25.8 \%)$ & $7 / 256$ (2.7\%) & $22 / 256(8.6 \%)$ & 256 & \\
\hline Yes & 142/295 (48.1\%) & 27/295 (9.2\%) & $84 / 295$ (28.5\%) & 27/295 (9.2\%) & 15/295 (5.1\%) & 295 & \\
\hline Total & 250 & 80 & 150 & 34 & 37 & 551 & \\
\hline Sanitary water & & & & & & & 0.333 \\
\hline No & 70/146 (47.9\%) & 15/146 (10.3\%) & $41 / 146$ (28.1\%) & 13/146 (8.9\%) & 7/146 (4.8\%) & 146 & \\
\hline Yes & $217 / 473$ (45.9\%) & 69/473 (14.6\%) & 131/473 (27.7\%) & 25/473 (5.3\%) & $31 / 473(6.6 \%)$ & 473 & \\
\hline Total & 287 & 84 & 172 & 38 & 38 & 619 & \\
\hline Housewife mothers & & & & & & & 0.843 \\
\hline No & 187/413 (45.3\%) & $56 / 413(13.6 \%)$ & 114/413 (27.6\%) & $27 / 413(6.5 \%)$ & 29/413 (7.0\%) & 413 & \\
\hline Yes & $67 / 144$ (46.5\%) & 24/144 (16.7\%) & $37 / 144$ (25.7\%) & 8/144 (5.6\%) & 8/144 (5.6\%) & 144 & \\
\hline Total & 254 & 80 & 151 & 35 & 37 & 557 & \\
\hline Mean Family size & 4.02 & 4.45 & 4.04 & 3.64 & 4.34 & $4.1^{\mathrm{a}}$ & 0.026 \\
\hline
\end{tabular}

${ }^{\mathrm{a}}$ Mean of the five groups; significant $p$-values are made bold

67\% identified by Valenzuela et al. in Chile in 2018, however they used the Film Array Gastrointestinal panel diagnostic technique [24]. Data from other Middle Eastern countries showed AGE causing enteropathogens' prevalence rates of 28\% in Bahrain [25], 63\% in Palestine [26], 53.4\% in Saudi Arabia [27], and 57.6\% in Lebanon [20]. Out of the $332(53.6 \%)$ detected pathogen-infected AGE cases, $88.55 \%(n=294 / 332)$ were due to a single pathogen infection while $11.45 \%(n=38 / 332)$ were due to mixed pathogens, which is higher than the number of co-infections obtained by an Italian study in 2018 (2.3\%) [28] and much lower than the number of concurrent infections provided by Shrivastava et al. from Odisha, India in 2017 (33.8\%) [29].
Of all the pathogenic agents detected in our study, $E$. histolytica was the lead AGE-causing enteropathogen with $27.8 \%$ of the cases $(n=172$ of 619$)$, which is very close to the results obtained in our previous study (26.3\%) [20] and similar to the prevalence reported previously from Lebanon in 2013 (22.3\%) [14]. Our findings also supported previous regional studies as the prevalence of E. histolytica among individuals (regardless of their age) was found to be $20.0 \%$ in Saudi Arabia [16] and $19.9 \%$ in Libya [30]. Moreover, the age distribution of E. histolytica infection was as follow: $65.1 \%(112 / 172)$ below 2 years of age; these results are uncommon in this age group since $E$. histolytica is usually transmitted via the fecal oral route with contaminated food and water, so young children are less 

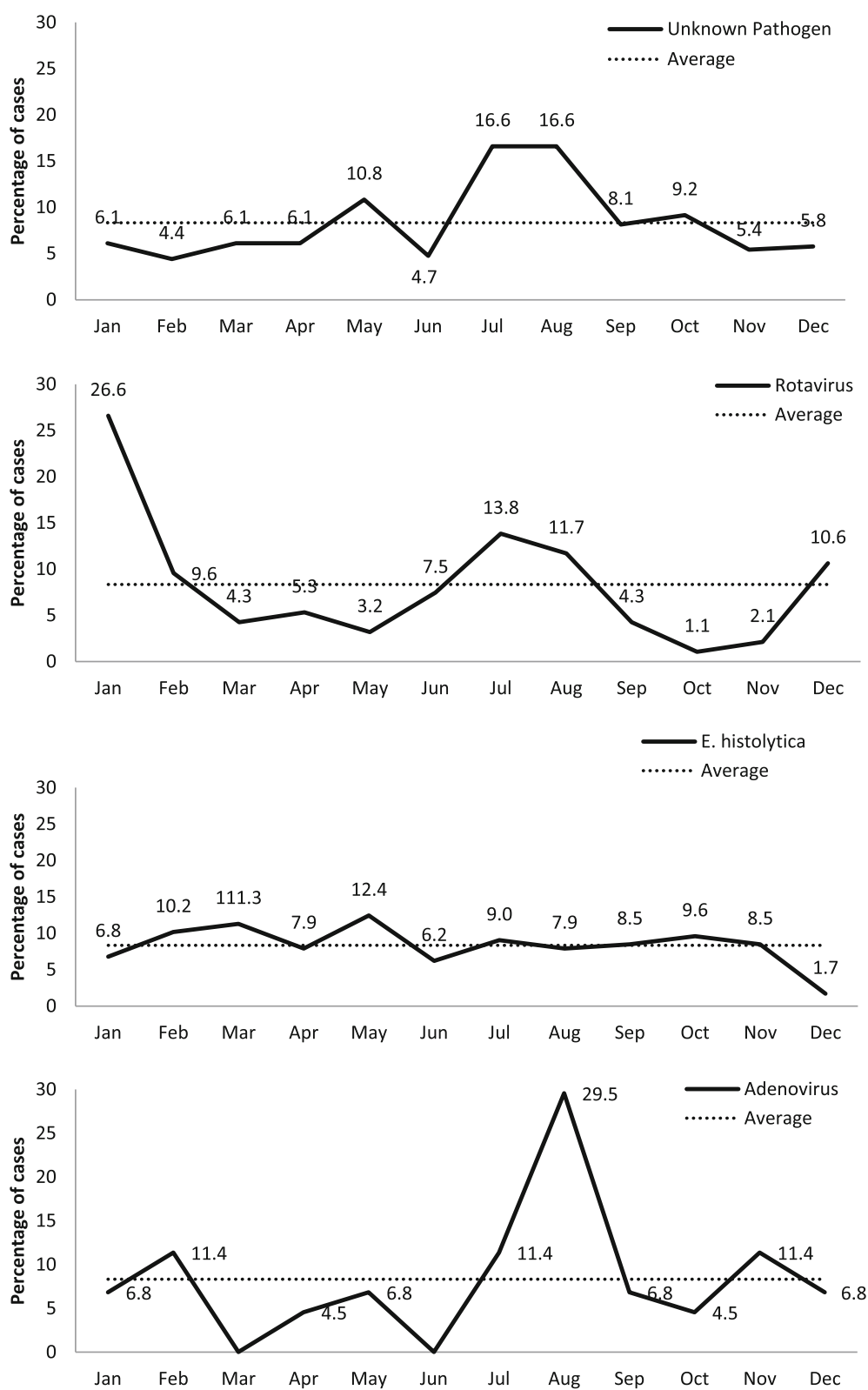

Fig. 2 Percentage of cases of each enteropathogen according to the month of admission

prone to develop such infection regularly [31]. This may indicate that the drinking water used for milk preparation and the tap water used for daily home and body hygiene might be contaminated and orally ingested by babies during bathing or face washing. In fact, low socio-economic status is the most important demographic factor linked to the high occurrence of E. histolytica among children and this is probably due to low level of public and individual hygiene [32].

Concerning clinical manifestations, $83.1 \%$ of the patients with amoebiasis had high fever and severe diarrhea, and $38.4 \%$ complained of vomiting which are significantly higher compared to patients from the rotavirus group, adenovirus group and the mixed group ( $p=0.001$ for fever, $p=0.016$ for diarrhea, and $p<0.001$ for vomiting). Naous et al. in 2013 showed that $94.2 \%$ of patients infected with E. histolytica had fever [14]. Furthermore, we have found that this group has the highest Vesikari score $(11.8 \pm 1.6)$ compared to the other groups $(p=0.005)$. In addition, this group showed the highest CRP level (66.7 $\mathrm{mg} / \mathrm{dL})$ when compared to other groups $(p<0.001)$ and this is a common finding since $E$. histolytica infection is linked to high CRP levels due to the pathogen's invasive nature [33]. This indicates that among our 4 groups of identified pathogens, E. histolytica is responsible for the most severe AGE. Regarding the monthly distribution of 
Table 2 Clinical and laboratory data of patients

\begin{tabular}{|c|c|c|c|c|c|c|c|}
\hline Clinical Characteristics & $\begin{array}{l}\text { Unidentified } \\
\text { group I }\end{array}$ & $\begin{array}{l}\text { rotavirus } \\
\text { group II }\end{array}$ & $\begin{array}{l}\text { E. histolytica } \\
\text { group III }\end{array}$ & $\begin{array}{l}\text { adenovirus } \\
\text { group IV }\end{array}$ & $\begin{array}{l}\text { Mixed } \\
\text { group V }\end{array}$ & Total & $P$-value \\
\hline Frequency (\%) & $287(46.4 \%)$ & $84(13.6 \%)$ & $172(27.8 \%)$ & $38(6.1 \%)$ & $38(6.1 \%)$ & 619 & - \\
\hline \multicolumn{8}{|l|}{ Clinical Manifestations } \\
\hline Fever & $215(74.9 \%)$ & $52(61.9 \%)$ & $143(83.1 \%)$ & $22(57.9 \%)$ & $26(68.4 \%)$ & 458 & 0.001 \\
\hline Vomiting & $112(39.0 \%)$ & $53(63.1 \%)$ & $66(38.4 \%)$ & $22(57.9 \%)$ & $24(63.2 \%)$ & 277 & 0.000 \\
\hline Diarrhea & $208(72.5 \%)$ & $69(82.1 \%)$ & $144(83.7 \%)$ & $33(86.8 \%)$ & $29(76.3 \%)$ & 483 & 0.016 \\
\hline Vesikari score (Mean \pm SD) & $11.2 \pm 1.8$ & $11.4 \pm 1.5$ & $11.8 \pm 1.6$ & $11.2 \pm 1.6$ & $11.3 \pm 1.8$ & - & 0.005 \\
\hline Duration of hospitalization per days (Mean \pm SD) & $2.7 \pm 1.2$ & $2.9 \pm 1.1$ & $2.9 \pm 1.2$ & $3.3 \pm 2.1$ & $3.4 \pm 1.3$ & $3.04^{\mathrm{a}}$ & 0.003 \\
\hline \multicolumn{8}{|l|}{ Laboratory Findings } \\
\hline WBCs $\left(\times 10^{3}\right.$ per $\left.\mathrm{mm}^{3}\right)$ & $2.79 \pm 3.85$ & $2.29 \pm 3.04$ & $12.23 \pm 4.98$ & $1.92 \pm 2.29$ & $7.15 \pm 6.76$ & - & 0.000 \\
\hline RBCs (million per $\mathrm{mm}^{3}$ ) & $1.47 \pm 1.88$ & $1.53 \pm 2.06$ & $7.10 \pm 5.45$ & $1.14 \pm 1.01$ & $3.19 \pm 3.99$ & - & 0.000 \\
\hline $\mathrm{HGB}$ (in mg/dL; mean $\pm \mathrm{SD}$ ) & $11.7 \pm 2.4$ & $11.5 \pm 1.2$ & $12.6 \pm 8.4$ & $12.1 \pm 1.0$ & $11.5 \pm 1.1$ & - & 0.008 \\
\hline $\mathrm{HCT}$ (in \%; mean $\pm \mathrm{SD}$ ) & $33.5 \pm 4.1$ & $33.9 \pm 3.2$ & $34.0 \pm 4.2$ & $34.8 \pm 4.7$ & $34.1 \pm 2.9$ & - & 0.027 \\
\hline $\mathrm{BS}$ (in mg/dL; mean $\pm \mathrm{SD}$ ) & $91.1 \pm 28.3$ & $77.1 \pm 20.1$ & $97.5 \pm 19.2$ & $86.0 \pm 27.7$ & $87.3 \pm 19.1$ & - & 0.000 \\
\hline CRP (in mg/dL; mean $\pm \mathrm{SD}$ ) & $49.5 \pm 65.9$ & $28.0 \pm 61.4$ & $66.3 \pm 67.4$ & $11.7 \pm 20.0$ & $43.7 \pm 85.9$ & - & 0.000 \\
\hline
\end{tabular}

Abbreviations: WBCs White blood cells, RBCS Red blood cells, HGB Hemoglobin, HCT Hematocrit, BS Blood sugar, CRP C-reactive protein

${ }^{a}$ Mean of the five groups; significant $p$-values are made bold

E. histolytica, it was shown to have small fluctuations around its yearly average with two short peaks during March (11.3) and May (12.4) indicating that the chances of $E$. histolytica infection are similar throughout the year.

The second major enteropathogen identified in our study was rotavirus, responsible for $13.6 \%(n=84 / 619)$ of the cases diagnosed with AGE which is not far from the $19.6 \%$ previously reported in 2017 in Saudi Arabia [27] and lower than the previous reported results (26\%) in 2017 in India [29]. Rotavirus is responsible for the hospitalization of more than 2 million individuals and for the death of over half a million patients form AGE in infants and young children worldwide, especially in developing countries in Africa and Asia [34].

Concerning age distribution, $13.6 \%(n=84 / 619)$ of our reported AGE cases below 5 years of age were due to rotavirus which is in line with several studies from the Eastern Mediterranean region [35, 36]. Compared to its yearly average, rotavirus is more prevalent in January with a total of 27 cases admitted to the hospital during that month. In fact, several studies have shown higher rotavirus AGE incidence during the period between January and June [37]. In general, rotavirus is known to cause diarrheal illness throughout the year but predominantly during winter months in countries with temperate climates such as Lebanon. Like other diarrheal viruses, rotavirus spreads mainly through the contact with contaminated surfaces, ingestion of contaminated food or water and contact with infected persons [38].

Adenoviruses are abundant agents known to cause digestive infection in children under the age of 5 , usually due to poor personal hygiene or the ingestion of contaminated food or water [39]. In our study, we have identified the presence of adenovirus as a single agent in $6.1 \%$ of the cases, a percentage that is equal to that of the mixed group and similar to the adenovirus prevalence reported in a previous study from Korea in 2017 [40]. Our results demonstrated a significant high prevalence of adenoviral infections in August represented with a major peak of 29 cases reported during that

Table 3 Results of the logistic regression analysis with infectious agents as dependent variables according to breast-feed, Rotavaccine, and sanitary water

\begin{tabular}{|c|c|c|c|c|c|c|c|c|c|c|}
\hline \multirow{2}{*}{$\begin{array}{l}\text { Independent } \\
\text { variables }\end{array}$} & \multicolumn{2}{|c|}{ Unidentified group I } & \multicolumn{2}{|c|}{ rotavirus group II } & \multicolumn{2}{|c|}{ E. histolytica group III } & \multicolumn{2}{|c|}{ adenovirus group IV } & \multicolumn{2}{|c|}{ Mixed group V } \\
\hline & OR & $95 \% \mathrm{Cl}$ & OR & $95 \% \mathrm{Cl}$ & OR & $95 \% \mathrm{Cl}$ & OR & $95 \% \mathrm{Cl}$ & OR & $95 \% \mathrm{Cl}$ \\
\hline Breast-feed* ${ }^{*}$ & 0.866 & $0.606-$ & 1.013 & $0.608-$ & 1.668 & $1.089-$ & 0.592 & $0.295-$ & 0.655 & $0.331-$ \\
\hline$p$-value & 0.431 & 1.238 & 0.959 & 1.688 & 0.019 & 2.555 & 0.139 & 1.185 & 0.223 & 1.294 \\
\hline Rotavirus vaccine* & 1.224 & $0.875-$ & 0.377 & $0.229-$ & 1.114 & $0.765-$ & 3.505 & $1.500-$ & 0.558 & $0.283-$ \\
\hline$p$-value & 0.238 & 1.712 & 0.000 & 0.621 & 0.573 & 1.624 & 0.004 & 8.191 & 0.092 & 1.100 \\
\hline Sanitary water* & 0.930 & $0.643-$ & 1.500 & $0.830-$ & 0.988 & $0.654-$ & 0.574 & $0.286-$ & 1.400 & $0.603-$ \\
\hline$p$-value & 0.700 & 1.346 & 0.180 & 2.710 & 0.955 & 1.92 & 0.119 & 1.153 & 0.433 & 3.249 \\
\hline
\end{tabular}

*Reference groups: Breast-feed (Yes), Rota-vaccine (Yes), and Sanitary water (Yes); significant $p$-values are made bold 
Table 4 Results of the logistic regression analysis with infectious agents as dependent variables according to different age groups

\begin{tabular}{|c|c|c|c|c|c|c|}
\hline \multirow[t]{2}{*}{ Infectious Agents } & \multicolumn{6}{|c|}{ Age groups (in months) } \\
\hline & $1-3$ & $4-11$ & $12-23$ & $24-35$ & $36-47$ & $48-60$ \\
\hline $\begin{array}{l}\text { Unidentified group I: } \\
\text { OR }(95 \% \mathrm{Cl}) ; P \text {-value }\end{array}$ & $\begin{array}{l}1.343(0.656-2.753) \\
0.420\end{array}$ & $\begin{array}{l}0.819(0.471-1.425) \\
0.480\end{array}$ & $\begin{array}{l}0.931(0.534-1.623) ; \\
0.801\end{array}$ & $\begin{array}{l}1.252(0.677-2.314) \\
0.474\end{array}$ & $\begin{array}{l}0.966(0.480-1.944) ; \\
0.922\end{array}$ & 1.000 \\
\hline $\begin{array}{l}\text { rotavirus group II: } \\
\text { OR }(95 \% \mathrm{Cl}) ; P \text {-value }\end{array}$ & $\begin{array}{l}1.782(0.454-6.989) ; \\
0.407\end{array}$ & $\begin{array}{l}2.865(0.962-8.532) \\
0.059\end{array}$ & $\begin{array}{l}3.024(1.015-9.012) \\
\mathbf{0 . 0 4 7}\end{array}$ & $\begin{array}{l}2.168(0.661-7.113) ; \\
0.202\end{array}$ & $\begin{array}{l}4.467(1.355-14.726) ; \\
\mathbf{0 . 0 1 4}\end{array}$ & 1.000 \\
\hline $\begin{array}{l}\text { E. histolytica group } \\
\text { III: OR ( } 95 \% \text { Cl); P-value }\end{array}$ & $\begin{array}{l}0.724 \text { (0.339-1.547); } \\
0.405\end{array}$ & $\begin{array}{l}0.637(0.356-1.137) ; \\
0.127\end{array}$ & $\begin{array}{l}0.605(0.336-1.087) ; \\
0.093\end{array}$ & $\begin{array}{l}0.484(0.247-0.952) \\
\mathbf{0 . 0 3 5}\end{array}$ & $\begin{array}{l}0.390(0.173-0.879) \\
\mathbf{0 . 0 2 3}\end{array}$ & 1.000 \\
\hline $\begin{array}{l}\text { adenovirus group IV: } \\
\text { OR }(95 \% \text { CI); } P \text {-value }\end{array}$ & $\begin{array}{l}2.800(0.247-31.733) ; \\
0.406\end{array}$ & $\begin{array}{l}5.060(0.646-39.664) \\
0.123\end{array}$ & $\begin{array}{l}3.006(0.363-24.893) ; \\
0.307\end{array}$ & $\begin{array}{l}7.241(0.896-58.535) ; \\
0.063\end{array}$ & $\begin{array}{l}9.800(1.169-82.176) ; \\
\mathbf{0 . 0 3 5}\end{array}$ & 1.000 \\
\hline $\begin{array}{l}\text { Mixed group V: OR } \\
(95 \% \text { Cl); } P \text {-value }\end{array}$ & $\begin{array}{l}0.328(0.036-3.028) ; \\
0.326\end{array}$ & $\begin{array}{l}1.654(0.533-5.132) ; \\
0.383\end{array}$ & $\begin{array}{l}1.387(0.436-4.409) ; \\
0.579\end{array}$ & $\begin{array}{l}0.356(0.063-2.002) \\
0.241\end{array}$ & $\begin{array}{l}0.299(0.032-2.754) \\
0.287\end{array}$ & 1.000 \\
\hline
\end{tabular}

Significant $p$-values are made bold

month; this peak during the summer season may be due to certain viral characteristics such as environmental stability, heat resistance, easy transmission by the fecal-oral route and more likely due to the increased intake of water during this period which could be contaminated.

Regarding the various clinical manifestations, only 57.9 and $61.9 \%$ of the cases in both the adenovirus and the rotavirus groups were diagnosed with high grade fever, respectively, and a very low CRP value $(28.0 \mathrm{mg} / \mathrm{dL}$ for rotavirus and $11.7 \mathrm{mg} / \mathrm{dL}$ for adenovirus) which are less than the values observed in either the $E$. histolytica group or the unidentified group. Although similar to groups I (Unidentified group) \& III (E. histolytica group), $82.1 \%$ of the cases infected with rotavirus and $86.8 \%$ of the cases infected with adenovirus were diagnosed with diarrhea which is considered a hallmark of AGE. Considering the Vesikari score, we found that both groups II (rotavirus group) and IV (adenovirus group) had scores below that of group III (E. histolytica group) indicating that rotavirus and adenoviral infection cause AGE with lower severity when compared to other enteropathogens.

In our study, we have recognized $46.4 \%$ of cases with unidentified causes or pathogens, a notable percentage that we must depend on to initiate further needed tests to improve our pathogen identification ability. Clinical manifestations of patients within this group have shown a strong prevalence of high-grade fever (74.9\%) and diarrhea (72.5\%) with an approximately high CRP value $(49.5 \mathrm{mg} / \mathrm{dL})$, all of which highly suggest the possibility of invasive infections as major AGE-causing enteropathogens within the group [33]. Despite the potentially low Vesikari score (11.2) tabulated for this group compared to the other groups, Vesikari score of 11 or more still indicates severe AGE. In fact, unidentified pathogens can include different viral strains, bacteria, and parasites, each of which may cause AGE with a certain severity depending on the causing agent. As a result, to improve our pathogen detection ability, we need to widen our test panel by increasing the number of cultures performed for hospitalized children with suspected invasive
AGE in order to foster more pathogenic bacteria such as Salmonella, Campylobacter, Shigella or to cultivate more pathogenic viruses such as norovirus, astrovirus or to detect other pathogenic parasites such as Giardia lamblia and Cryptosporidium species, all of which can be potential causes of AGE within the unidentified pathogen group. A recent study by Ibrahim el al. showed, by using of microbiological and molecular diagnosis techniques, a prevalence of 21.5\% of Campylobacter species in stool of Lebanese patients with AGE. This type of diagnosis must be implicated as a routine diagnosis test in future studies [41].

The average length of hospital stays (LOS) is 3.04 days and it was approximately similar in the different groups. Furthermore, our study showed that breastfed children might be less prone to unidentified enteropathogens, adenovirus and mixed infections. However, breastfeeding did not affect their susceptibility for rotavirus infection $(\mathrm{OR}=1.013,95 \%$ CI [0.608-1.688], $p=0.959)$ while it was found to be associated with high rates of E. histolytica infection $(\mathrm{OR}=1.668,95 \%$ CI [1.089-2.555], $p=0.019)$. Despite this, it is known that colostrum and mature human milk can significantly kill $E$. histolytica by bile salt-stimulated lipase in human milk that kills both parasites; Giardia lamblia and E. histolytica [42]. Such result may be attributed to insufficient maternal hygiene or associated improper feeding practices. Finally, drinking sanitary water had no protective effect on any given group, and this may be due to use of contaminated tap water for daily cooking and personal hygiene.

\section{Study limitations}

We believe that our study has a number of limitations. First, the diagnostic tests were limited to the routine ones that are dependent on their availability in the participating tertiary healthcare hospitals of our study. Most of the time, the bacterial coproculture was not requested routinely on admission (it was only done if requested by the treating physician (in $11.3 \%$ of cases)). Second, the low 
sensitivity of microscopy in differentiating $E$. histolytica from other morphologically-similar amoebae like E. dispar and E. moshkovskii is also considered as a limitation. In fact, although WHO states that $E$. histolytica stool antigen detection test is more specific for the pathogenic amoeba $E$. histolytica than the classic stool ova and parasite examination, the latter was the one still utilized in almost all healthcare centers in South Lebanon, including the three tertiary healthcare centers in our study, which reflects the importance of improving health services in this unfortunate area of the world (South Lebanon). Third, we believe that we have an important group of unidentified pathogens that should solicit us to expand our diagnostic arsenal. Lastly, some data were missing from the medical records of the patients, such as details about breastfeeding (exclusive or not, and duration of exclusive breastfeeding).

\section{Conclusion}

In conclusion, increasing the size of the AGE diagnostic panel may allow us to detect specific pathogens causing both invasive and non-invasive entero-colitis in hospitalized children. Consequently, we will be able to prescribe the specific treatment for each case alone. Providing a personalized treatment depending on the exact cause of infection is considered a more efficient compared to the prescription of the broad-spectrum antibiotics.

\section{Abbreviations}

AGE: Acute gastroenteritis; BS: Blood sugar; CRP: C-reactive protein; EMB: Eosin methylene blue; HCT: Hematocrit; HGB: Hemoglobin; IRB: Institutional Review Board; LOS: The average length of hospital stays; LU: Lebanese University; SPSS, Inc.: Statistical Package for Social Science software; SS: Salmonella-Shigella; WHO: World Health Organization

\section{Acknowledgements}

We would like to thank first all the parents of children who were enrolled in this study and accepted to give us the requested information. Secondly, we would like to express our gratitude thanks to the healthcare centers and LU for their support in the conduction of this study.

\section{Funding}

Not funded.

\section{Availability of data and materials}

The datasets used and/or analyzed during the current study are available from the corresponding author on reasonable request.

\section{Authors' contributions}

AS, HF, MC, LS, and HFB contributed to the project design, data collection and entry, analysis of results, and writing of manuscript. GG and AS contributed to the study conception, study design, proposal development, oversight of data collection, data entry, data review, data analysis, interpretation, and review of manuscript drafts, revision and approval of final versions submitted for publication. All authors critically revised and edited the manuscript, and approved the final draft.

\section{Ethics approval and consent to participate}

The study with all its experimental protocols was conducted under the Institutional Review Board (IRB) approval of the Lebanese University (LU) and the Ethics Committee of the healthcare centers. Ethical clearance was taken as per the norms and in accordance with relevant guidelines and regulations of the LU and the tertiary healthcare centers included. Recruitment was done randomly after obtaining a written informed consent from the patients care givers. In accordance with the Declaration of Helsinki, parents of all patients enrolled in this cross-sectional clinical study provided written informed consents for participation.

\section{Consent for publication}

Not Applicable.

\section{Competing interests}

The authors declare that they have no competing interests or biomedical financial or non-financial interests.

\section{Publisher's Note}

Springer Nature remains neutral with regard to jurisdictional claims in published maps and institutional affiliations.

\section{Author details}

${ }^{1}$ Rammal Hassan Rammal Research Laboratory, Physio-toxicity (PhyTox) Research Group, Lebanese University, Faculty of Sciences (V), Nabatieh, Lebanon. ${ }^{2}$ Department of Pediatrics, Faculty of Medical Sciences, Lebanese University, Beirut, Lebanon. ${ }^{3}$ Department of Biology, Faculty of Arts and Sciences, American University of Beirut, Beirut, Lebanon. ${ }^{4}$ Faculty of Medicine, Beirut Arab University, Beirut, Lebanon. ${ }^{5}$ Department of Anatomy, Cell Biology, and Physiological Sciences, Faculty of Medicine, American University of Beirut, Beirut, Lebanon.

Received: 11 February 2019 Accepted: 12 April 2019

Published online: 30 April 2019

\section{References}

1. Harb H. The Statistical Bulletin of the Ministry of Public Health (MOPH) 2017. In: Statistical Bulletins of the MoPH. Beirut: Ministry of Public Health (MoPH), World Health Organization (WHO); 2017.

2. World Health Organization. Global Health Observatory data repository 2018. Geneva: World Health Organization; 2018.

3. Stuempfig ND, Seroy J. Gastroenteritis, Viral. In: StatPearls. Treasure Island: StatPearls Publishing. p. 2018.

4. Freedman SB, Ali S, Oleszczuk M, Gouin S, Hartling L. Treatment of acute gastroenteritis in children: an overview of systematic reviews of interventions commonly used in developed countries. Evid Based Child Health Cochrane Rev J. 2013:8(4):1123-37.

5. Kinlin LM, Bahm A, Guttmann A, Freedman SB. A survey of emergency department resources and strategies employed in the treatment of pediatric gastroenteritis. Acad Emerg Med Off J Soc Acad Emerg Med. 2013;20(4):361-6.

6. Shane AL, Mody RK, Crump JA, Tarr PI, Steiner TS, Kotloff K, Langley JM, Wanke C, Warren CA, Cheng AC, et al. 2017 Infectious Diseases Society of America clinical practice guidelines for the diagnosis and Management of Infectious Diarrhea. Clin Infect Dis. 2017;65(12):1963-73.

7. Diarrhoea: why children are still dying and what can be done [https://apps. who.int/iris/bitstream/handle/10665/44174/9789241598415_eng. pdf? sequence=1 Accessed on Feb 2019].

8. Chow CM, Leung AK, Hon KL. Acute gastroenteritis: from guidelines to real life. Clin Exp Gastroenterol. 2010;3:97-112.

9. Albrecht L, Hartling L, Scott SD. Pediatric acute gastroenteritis: understanding caregivers' experiences and information needs. CJEM. 2016;19(3):198-206.

10. Kotloff KL, Nataro JP, Blackwelder WC, Nasrin D, Farag TH, Panchalingam S, Wu Y, Sow SO, Sur D, Breiman RF, et al. Burden and aetiology of diarrhoeal disease in infants and young children in developing countries (the global enteric multicenter study, GEMS): a prospective, case-control study. Lancet (London, England). 2013;382(9888):209-22.

11. Parashar UD, Hummelman EG, Bresee JS, Miller MA, Glass RI. Global illness and deaths caused by rotavirus disease in children. Emerg Infect Dis. 2003; 9(5):565-72.

12. Parashar U, Steele D, Neuzil K, Quadros C, Tharmaphornpilas P, Serhan F, Santosham M, Patel M, Glass R. Progress with rotavirus vaccines: summary of the tenth international rotavirus symposium. Expert Rev Vaccines. 2013;12(2):113-7.

13. Dbaibo G, Rajab M, Inati A, Mikhael R, Choueiry E, Al-Tannir M, Salam O, Ramakrishnan G, DeAntonio R. Hospital-based surveillance study of rotavirus gastroenteritis in children under 5 years of age in Lebanon. Trials Vaccinol. 2013;2:25-30 
14. Naous A, Naja Z, Zaatari N, Kamel R, Rajab M. Intestinal amebiasis: a concerning cause of acute gastroenteritis among hospitalized lebanese children. N Am J Med Sci. 2013;5(12):689-98.

15. Szajewska H, Dziechciarz P. Gastrointestinal infections in the pediatric population. Curr Opin Gastroenterol. 2010;26(1):36-44.

16. Hegazi MA, Patel TA, El-Deek BS. Prevalence and characters of Entamoeba histolytica infection in Saudi infants and children admitted with diarrhea at 2 main hospitals at South Jeddah: a re-emerging serious infection with unusual presentation. Braz J Infect Dis. 2013;17(1):32-40.

17. Pham Duc P, Nguyen-Viet H, Hattendorf J, Zinsstag J, Dac Cam P, Odermatt $P$. Risk factors for Entamoeba histolytica infection in an agricultural community in Hanam province, Vietnam. Parasit Vectors. 2011:4:102.

18. NIAID Emerging Infectious Diseases/Pathogens. [http://www.niaid.nih.gov/ topics/biodefenserelated/biodefense/pages/cata.aspx Accessed Feb 2019].

19. World Health Organization. Diarrhoeal disease. Geneva: World Health Organization; 2017.

20. Ghssein G, Salami A, Salloum L, Chedid P, Joumaa WH, Fakih H. Surveillance study of acute gastroenteritis etiologies in hospitalized children in South Lebanon (SAGE study). Pediatric Gastroenterol Hepatol Nutr. 2018;21(3):176-83.

21. Ruuska T, Vesikari T. Rotavirus disease in Finnish children: use of numerical scores for clinical severity of diarrhoeal episodes. Scand J Infect Dis. 1990;22(3):259-67.

22. Rotavirus + Adenovirus detection kit. In: Combo Cards. Zaragoza: CerTest; Biotec; 2018.

23. Youssef M, Shurman A, Bougnoux M, Rawashdeh M, Bretagne S, Strockbine N. Bacterial, viral and parasitic enteric pathogens associated with acute diarrhea in hospitalized children from northern Jordan. FEMS Immunol Med Microbiol. 2000;28(3):257-63.

24. Valenzuela C, Legarraga P, Peña A, Arenas A, Berkowitz L, Ramírez G, Wozniak A, García P, Álvarez-Lobos M. Etiologic and clinical characterization of community acquired gastroenteritis in adult patients in a Chilean emergency room by the FilmArray Gl panel. PLoS One. 2018;13(11):e0207850.

25. Ismaeel AY, Jamsheer AE, Yousif AQ, Al-Otaibi MA, Botta GA. Causative pathogens of severe diarrhea in children. Saudi Med J. 2002;23(9):1064-9.

26. Abu-Elamreen FH, Abed AA, Sharif FA. Viral, bacterial and parasitic etiology of pediatric diarrhea in Gaza, Palestine. Med Princ Pract. 2008;17(4):296-301.

27. Hawash YA, Ismail KA, Almehmadi M. High frequency of enteric protozoan, viral, and bacterial potential pathogens in community-acquired acute diarrheal episodes: evidence based on results of Luminex gastrointestinal pathogen panel assay. Korean J Parasitol. 2017;55(5):513-21.

28. Biscaro V, Piccinelli G, Gargiulo F, laniro G, Caruso A, Caccuri F, De Francesco MA. Detection and molecular characterization of enteric viruses in children with acute gastroenteritis in northern Italy. Infect Genet Evol. 2018;60:35-41.

29. Shrivastava AK, Kumar S, Mohakud NK, Suar M, Sahu PS. Multiple etiologies of infectious diarrhea and concurrent infections in a pediatric outpatientbased screening study in Odisha, India. Gut Pathogens. 2017;9:16.

30. Ghenghesh KS, Ghanghish K, BenDarif ET, Shembesh K, Franka E. Prevalence of Entamoeba histolytica, Giardia lamblia, and Cryptosporidium spp. in Libya: 2000-2015. Libyan J Med. 2016;11:32088.

31. Nikkan DY, llikkan B, Vural M. Amebiasis in infancy in the middle-high socioeconomic class in Istanbul, Turkey. Pediatr Infect Dis J. 2005;24(10):929-30.

32. Pestehchian N, Nazary M, Haghighi A, Salehi M, Yosefi H. Frequency of Entamoeba histolytica and Entamoeba dispar prevalence among patients with gastrointestinal complaints in Chelgerd city, southwest of Iran $\left({ }^{*}\right)$. J Res Med Sci. 2011;16(11):1436-40.

33. Borgnolo G, Barbone F, Guidobaldi G, Olivo G. C-reactive protein in viral and bacterial gastroenteritis in childhood. Acta Paediatr. 1996;85(6):670-4.

34. Centers for Disease Control and Prevention (CDC). Rotavirus surveillance-worldwide, 2001-2008. MMWR Morb Mortal Wkly Rep. 2008;57(46):1255-7.

35. Nafi O. Rotavirus gastroenteritis among children aged under 5 years in Al Karak, Jordan. East Mediterr Health J = La revue de sante de la Mediterranee orientale = al-Majallah al-sihhiyah li-sharq al-mutawassit. 2010;16(10):1064-9.

36. Salwa I, A E-B, Mohamed M, El-Sheikh A, A E. Comparative study of rotavirus detection. Zagazig Univ Med J. 2017:20(6):1-9.

37. Leshem E, Tate JE, Steiner CA, Curns AT, Lopman BA, Parashar UD. Acute gastroenteritis hospitalizations among US children following implementation of the rotavirus vaccine. Jama. 2015;313(22):2282-4.

38. Mladenova Z, Steyer A, Steyer AF, Ganesh B, Petrov P, Tchervenjakova T, Iturriza-Gomara M. Aetiology of acute paediatric gastroenteritis in Bulgaria during summer months: prevalence of viral infections. J Med Microbiol. 2015:64(Pt 3:272-82
39. Sotelo-Coronado Jl, Flores-Aréchiga A, Llaca-Díaz J, Pérez-Chávez F, LozanoQuintanilla S, Casillas-Vega N. Associated microorganisms to gastrointestinal infections. Revista Latinoamericana de Patología Clínica y Medicina de Laboratorio. 2017;63(4):206-10.

40. Kim JS, Lee SK, Ko DH, Hyun J, Kim HS, Song W, Kim HS. Associations of adenovirus genotypes in Korean acute gastroenteritis patients with respiratory symptoms and intussusception. Biomed Res Int. 2017;2017: 1602054.

41. Ibrahim JN, Eghnatios E, El Roz A, Fardoun T, Ghssein G. Prevalence, antimicrobial resistance and risk factors for campylobacteriosis in Lebanon. J Infect Dev Ctries. 2019;13(01):11-20.

42. Akisu C, Aksoy U, Cetin H, Ustun S, Akisu M. Effect of human milk and colostrum on Entamoeba histolytica. World J Gastroenterol. 2004;10(5):741-2.
Ready to submit your research? Choose BMC and benefit from:

- fast, convenient online submission

- thorough peer review by experienced researchers in your field

- rapid publication on acceptance

- support for research data, including large and complex data types

- gold Open Access which fosters wider collaboration and increased citations

- maximum visibility for your research: over $100 \mathrm{M}$ website views per year

At BMC, research is always in progress.

Learn more biomedcentral.com/submissions 